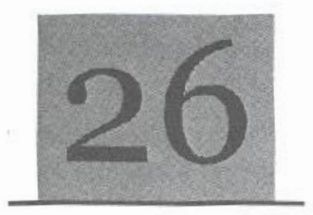

\title{
Challenges of inland artisanal fish production in Nigeria: economic perspective
}

\author{
Chilaka Q. M. / Nwabeze, G. O/Odili, O.E.
}

\begin{abstract}
Fishery prochuction is significunt to Nigerian economy in view of its roles in providing cheap source of foodinuirition security, income, employment, serves as source of foreign exchange particularly those of the riparian communities. Despite these significant roles, the fisheries subsector is faced with huge challenges, swch as: decreasing yield, inefficient management of fishing policy, inadequate technicul and commercial knowledge among others, thereby limiting its production potentials. The possibility of fish production especially artisanal fisheries to maich up with fish productivity in the economy depends on fishing operation, efficient use of labour; sustainable and efficient management of fishing policy. Therefore the essence of this study is to review the challenges in fish production in Nigeria: Economic perspective, with emphasis on the mo of fisheries in economic development, decreasing fish yield, market forces and resotsre inefficiency.
\end{abstract}

Keywords: Fishery, economic perspective, challenges and production.

\section{Introduction}

$\mathrm{F}$ ish production in Nigeria comes from three sources; artisanal (inland rivers, lakes, costal and brackish water), aquaculture (fish farm) and industrial fishing (Otubusin, 2011). However, the vast majority of the fish supply in most cases comes from the artisanal sub-sector. Fish production in Nigeria has not been consistent in all the sources (artisanal inland, aquaculture and industrial fishing). Total domestie fish production in Nigeria ranges between 242,525 and 615,507 metric tons from 1981 to 2007 and has not been consistent (FDF, 2008). In 1981 the artisanal fishery production was aboul 150,000 metric tons and dropped sharply to about 60,000 metric tons in 1985 (figure 1). Thereafter, it continued inereasing with fluctuations between 100,000 to 200,000 metric tons between 1996 and 2006 , and raised to about 240,000 metric tones in 2007 . On the other hand, aquaculture, which is fast developing in recent maintained a relatively steady rate of less than 50,000 metric tons from 1983 up to 2003 . The rapid growth in the aquaculture sub-sector in the last decade has led to a geometric increase in production ranging from less than 50,000 metric tons to morc than 100,000 metric tons between 2004 to 2010 (figure 1).

Nigeria, like many other countries in sub Saharan Africa is endowed with substantial marine and inland fisheries

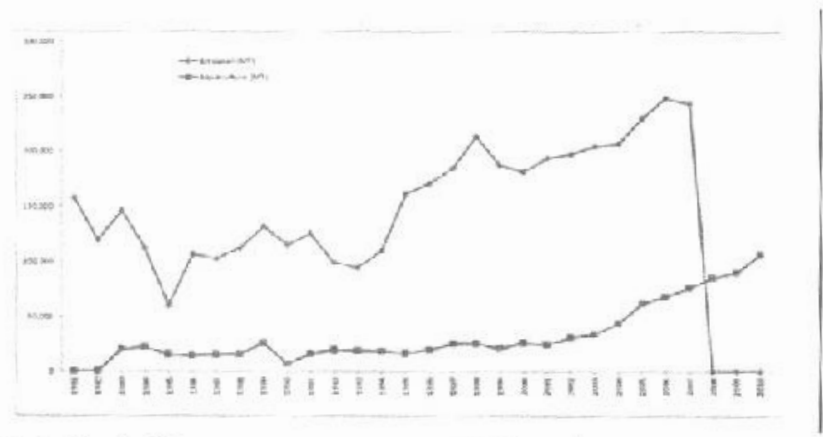

Fig. 1: Nigeria fish production from 1981-2010 as adapted by FDF, 2008. resources upon which the fisheries sector is based. Nigeria has a land area of $923,768 \mathrm{~km}$ with a continental shelf area of $47,934 \mathrm{Km}^{2}$ and a length of coast line of $853 \mathrm{Km}$. It also has a vast network of inland waters like rivers, flood plains, natural and man made lakes and reservoirs (Shimang, 2005). The inland water mass was estimated to be about 12.5 million hectares of inland waters capable of producing 512,000 metric tons of fish annually (Ita, 1984; and Shimang, 2005). The country remains one of the largest consumers of fish with demand estimate at 1.4 million metric tones. However, a demand supply gap of at least 0.7 million metric tones exists nationally with import making up the short fall at a cost of almost 0.5 billion dollars per year. Domestic fish production of about 500,000 metric tones is supplied 
by artisanal fishers $(85 \%)$, despite over fishing in many water bodies across the country (Adekoya, 2004). Fish production in Nigeria has not been consistent in all the sources (artisanal inland, aquaculture and industrial fishing). Total domestic fish production in Nigeria ranges between 242,525 and 615,507 metric tones from 1981 to 2007and has not been consistent (FDF, 2008). Despite these considerably high potentials, local fish production has failed to meet the country's domestic demand (FAO, 1995). The fish industry remains the most virgin investment in Nigeria compared with the importation of frozen fish in the domestic market ( $\mathrm{Ndu}, 2006$ ). Therefore the essence of this study is to review the challenges in fish production in Nigeria with emphasis on the role of fisheries in economic development, decreasing yield, market forces and resource inefficiency.

\section{Challenges of Artisanal Fish Production}

Artisanal fish production in Nigeria is faced with a number of challenges which includes:

- Over-fishing: Fish resources are susceptible to environmental and man induced stresses and can deteriorate rapidly, particularly when environment and man act concurrently to limit production. Collapse of fisheries due to overfishing has been well documented in lakes. However, many cases are recorded where fishing and environmental pressures have together produced such a collapse. In Lake Kainji, Seisay and du lieu (1997) observed a reduction in mean sizes (that is, mean length and weight) in fish species and changes in species composition due to both recruitment and ecosystem overfishing.

- Decreasing yield: This is occasioned by over exploitation and inefficiency of fisheries management policy. Why is it that over the last years, despite undeniable progress the ability to monitor and assess the state of fish stocks and understand the economic and social forces that underlie ecosystem change, the status of fishery resources has deteriorated? The slowly dawning awareness that managing fisheries is more to do with managing the people involved in fisheries than it is with managing the resource is one element of the answer, since rarely have issues of equity been resolved (Caddy, JF 1997). The reasons for the failure in the narrower sense, of resource management is not just a question of maintaining fishing mortality within sustainable limits for a series of target species, but recognizing the interconnectivity of ecosystems and the so far intractable problem of management of complex systems.

- Obnoxious fishing methods: The use of obnoxious fishing (practiced such as beach seine nets) has been observed as a challenge in sustaining the Kainji and Jebba Lakes (Scisay; Nwabeze, 2013)

- Multispecies fisherics: Managing fisheries may require considerable technical changes to the gear and fishing areas and seasons so as to increase selectivity and minimize impacts on other species.

\section{Economic Perspective of Challenges in Fish Production}

Economic analysis of the exploitation of natural resources applied to fisheries is a relatively recent branch of Economics, which itself is a very young and provisional science. 'This aspect has developed since the end of the 50 's (Gordon and Schaefer, 1957). On a simpler level it tries to explain the relationship between reproduction rale of a live resource, fishing effort as a cost and their relationship with calches expressed as revenue through sale of the resource (OECD, 1997). Figure 1 shows total cost, total revenue and profit afterwards with respect to fishing efforts and value. This shows how Total Revenue is balanced with Total Cost (TC) in an exploitation of a renewable resource. Total Revenue (TR) is no more than a potential biological production curve plotted against an external exploitation. The catches of a live resource multiplicd by their price lie behind the TR curve. This is why the curve reflects the typical reaction of a resource to the increase in capture due to an external factor. As the resource population density goes down, the effort needed to capture it goes up, as such the Cost of Effort is proportional to the effort in use in the sense that the higher the effort in use the higher the cost of production of each tonne caught, this will also affect the price at which the resource will be sold which affects the price stability in the fisheries sub sector and in turn affect market forces. We only need to consider that one unit of effort ( $\mathrm{a}$ man, a boat, a fishing day, a horsepower of steam, etc.) has a given implicit price in order to determine the total cost.

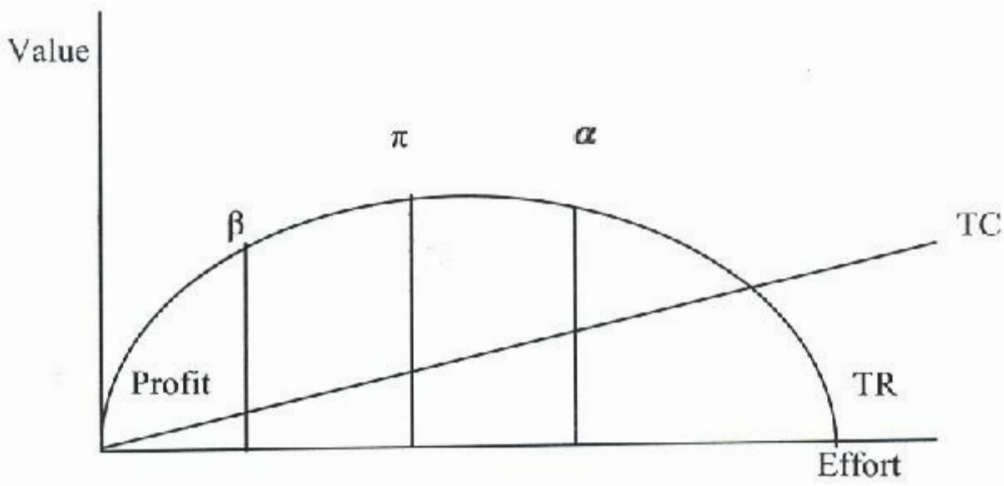

Fig. 2: Total cost and revenue with respect to fishing efforts and value as modified from Gordon-Scheafer Model, 1957)

From an economic perspective three relevant points which lead us to suppose that the exploitation will tend to be situated on two of them, according to the surrounding conditions. Figure 1 shows us three relevant points: $a, B, \pi$ an initial point 
$\pi$ indicates for us what the maximum sustainable biological yicld is. It is on the vertex of the Revenue function and represents the level of Exploitation (E) that generates a greater physical volume of captures and greater revenuc. The economic objective is not to increase revenue, but profit, which is the point where the difference between Income and Costs is at maximum. Point $\beta$ would represent maximum profit. In the case we are addressing now, this point would lie where the slopes of the Costs and Income become equal, which we will express in mathematical terms as the point with derived equals. This point maximizes the distance between TR and TC, between the money deposited and the money spent; therefore the profit is maximized. Any business wishing to maximize its profits will move towards this point if it can prevent another from increasing the effort, for example if it is private fishery exploitation. Therefore, if we are on point $\beta$, technically called Maximum Sustainable Yield (MSY), the condition that access to exploitation is regulated or property rights allocated must be fulfilled. In the case of open access if there are extra profits, other fishermen will arrive, attracted by these favourable expectations until the incentive disappears. In this case, the equilibrium point in a situation of open aecess is where cost is equal to revenue, moment after which the effort involves economic losses of which it will lead to resource inefficiency, decreasing yield and it will affect the forces of demand and supply negatively.

\section{Conclusion and Recommendation}

In the exploitation of fishing resources, the challenges are normally presented as excessive use: overfishing. In spite of the maximum economic yield being at a point where the fishing effort is catching less than could be caught sustainably, the competition between fishers encourages them to exploit the resource beyond its economic and biological possibilities. The possibility of fish production especially artisanal fisheries to mateh up with fish productivity in the economy depends on fishing operation, efficient use of labour, sustainable and efficient management of fishing policy and management tools such as restricting the effort of fishers through a set up of an efficient and effective administration to guide fishers in various communities.

From the foregoing, the following recommendations are made:

- Finance the definilive withdrawal that is paying the fishermen to abandon fishing activity and turn to other economic activities: farming, aquaculture among others. This evidently involves a cost for the government or administration but if it is regulated correctly it can reduce the effort involve in overfishing and to an extent help to tackle the challenges in fish production.

- Ensure adequate follow-up on the implementalion of fisheries laws and edits. This will be achieved through the involvement of the fishers.

\section{REFERENCES}

Adckoya B.B and Miller J.W. (2004): Fish cage culture potential in Nigeria-An overview. National Cultures, Agriculture Focus. $1(5)$ : 10.

Caddy JF.(1997): Fstablishing a consultative mechanism or arrangement for managing shared stocks within the jurisdiction of contiguous states. In: Proecedings of the Joint Workshop on Taking Stock: Defining and Measuring Shared Resources. Darwin, Australia, 1516 July, p. 81124.

Dada, B. F. (2004): Contribution of fisheries to employment, national economy and food sceurity in Nigeria. Presented at the 2003 FISON Public Leeture, Lagos, 22 December. Fish Network 1/1 6.

F.A. O. (1995): The State of World: Fishery and Agriculture. Fisheries Department, Rome.

(2009): .Fishery Department and Central Bank of Nigeria. Annual Repurt.

FDF (2008): Fisheries Statistics of Nigeria Fourth Fdition Federal Department of Fisheries Garki, Abuja, p.6

Gordon. M.S (1957): Some considerations of population dynamics and economics inrelation to the management of marine fisheries, Journal of Fisheries Research Board of Canada, vol. 14, no 5, 669-681

Ndu N. R. 2006. Fish Farm Layout, Pond Construction, Management and Maintenance-Hatchery Techniques. A paper presented at the National Workshop on the Principles and Icehniques of Fish Farming organized by Nigerian Agrieultural, Cooperative and Rural Development Bank Kaduna with collaboration of Life Riches Consulting.

Nwabeze, G.O (2013): Characterization of artisanal fishers livelihoods and the use of sustainable fisheries practices in the Jebba lake basin, Nigeria. NIFFR Annual Report (forthcoming).

OECD (1997): Towards sustainable fisheries, Fconomic Aspects of the management of living marine resources, Paris, 1997.

Otubusin, S. O. (2011): Inaugural lecture: Fish! Fish!! Fish!!! Department of Aquaculture and Fisheries Management, College of Environmental Resources Management (COLFRM). University of Agriculture, Abeokuta, Nigeria, 45-55.

Seisay, M. D. B. and T. A. du Feu (1997): The effect of long term exploitation by gill net fishery on the multi-species fish stoeks in Kainji Lake. Nigerian Germany Kainji Lake Fisheries Promotion Projeet Technical Report Series 11. 58p.

Shimang G.N. (2005): Fisheries Development in Vigeria, Problens and Prospects. A presentation by the Federal Director of Fisheries, in the Federal Ministry of Agriculture and Rural Development on Homcstead Fish

Farming Training for Serving and Retiring Public Servants in the Federal Ministry of Agriculture and Rural Development, FCT, Abuja. 